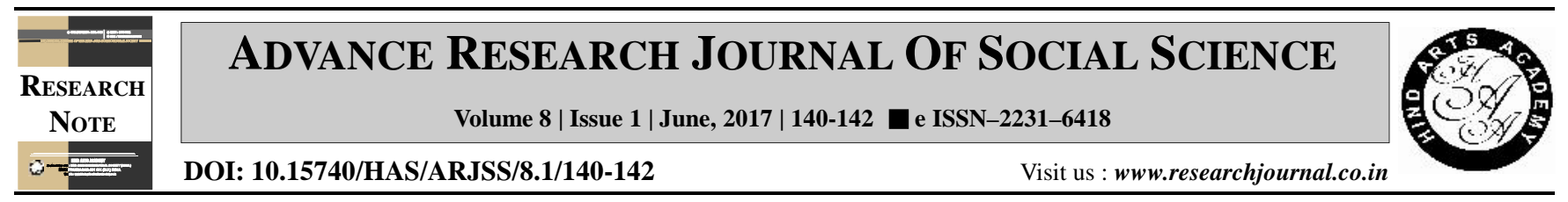

\title{
Effect of intervention on shoelace tying and buttoning of shirt skill of mentally retarded children
}

Lidya Ch. Momin* and Raj Pathania

Department of Human Development, College of Home Science, C.S.K. Himachal Pradesh Krishi Vishvavidyalaya, PALAMPUR (H.P.) INDIA

\section{ARTICLE INFO :}

Received : 28.02 .2017

Accepted : 30.05 .2017

\section{KEY WORDS :}

Shoelace tying, Buttoning, Skill, Mentally children, Shirt skill

\section{HOW TO CITE THIS ARTICLE :}

Momin, Lidya Ch. and Pathania, Raj (2017). Effect of intervention on shoelace tying and buttoning of shirt skill of mentally retarded children. Adv. Res. J. Soc. Sci., 8 (1) : 140-142, DOI: 10.15740/ HAS/ARJSS/8.1/140-142.

*Author for correspondence

\begin{abstract}
The present study was undertaken with specific objective to study the Impact of intervention on shoelace tying and buttoning of shirt skill of mentally retarded children. A total sample of 30 mentally retarded children was selected purposively from the Village Saliana, block of Panchrukhi of Kanga district in the state of Himachal Pradesh. It was found that significant improvement in shoelace tying and buttoning of shirt skill due to intervention. Hence the impact of intervention was found significant regarding shoelace tying and buttoning of shirt skill of mentally challenged children.
\end{abstract}

